\title{
Risky Sexual Behaviour among Big Construction Enterprise Workers; Bahir Dar City, Amhara Regional State, Northwest Ethiopia*
}

\author{
Mekibib Kassa $^{1}$, Eleni Tesfaye ${ }^{2}$, Zelalem Alamrew ${ }^{3}$ \\ ${ }^{1}$ Department of Public Health, KEA-MED Medical College, Addis Ababa, Ethiopia; ${ }^{2}$ Department of Nursing, College of Medicine \\ and Health Sciences, Gondar University, Gondar, Ethiopia; ${ }^{3}$ Department of Public Health, College of Medicine and Health Sciences, \\ Bahir Dar University, Bahir Dar, Ethiopia. \\ Email: mekibib15@yahoo.com, mekifikir3@gmail.com,kzolam@gmail.com
}

Received April 23 $3^{\text {rd }}, 2013$; revised May 21 ${ }^{\text {st }}, 2013$; accepted May 29 ${ }^{\text {th }}, 2013$

Copyright (c) 2013 Mekibib Kassa et al. This is an open access article distributed under the Creative Commons Attribution License, which permits unrestricted use, distribution, and reproduction in any medium, provided the original work is properly cited.

\begin{abstract}
Background: Risky sexual behaviors are the major factors in rising sexually transmitted infections among adolescents and young adults. In Ethiopia construction industry is on increasing and deriving young people from rural area to the cities. Therefore, the aim of this study was to determine the prevalence of risky sexual behaviour and factors associated with among construction workers. Methods: A cross sectional study was conducted in March 2012 among construction workers in Bahir Dar city. The analysis was carried out using SPSS version 16. The data were analyzed in bivariate and multivariate logistic regression. Result: The prevalence of risky sexual behavior among construction workers was $44.9 \%$. Female workers were about four times more likely to have had risky sexual practices than males (AOR $=3.86$, 95\% CI: 2.34 - 6.37). Respondents whose educational level less than fourth grade were 12 times more likely to be engaged in risky sex than whose educational level tenth grade or more (AOR $=12.13,95 \%$ CI: $1.84-79.78)$. Divorced individuals were about five times more likely to have had risky sexual activities than married individuals (AOR $=4.63$, 95\% CI: 1.32 - 16.12). Respondents whose first sexual commencement from 15 - 19 years were about three times more likely to have had risky sexual behavior than from $20-24$ years (AOR $=2.89,95 \%$ CI: $1.70-4.91$ ). Besides, the odds of having risky sexual behaviour among construction workers who had sexual partner at the time of the study were about 0.6 times less likely to have had risky sexual behaviours than workers who did not have (AOR $=0.6,95 \%$ CI: $0.38,0.96)$. Conclusion: The prevalence of risky sexual behavior among construction workers was $44.9 \%$. Variables such as sex, educational level, marital status, age at first sexual intercourse, presence of current sexual partner and casual sex were found to be independent predictors of risky sexual behaviour. Therefore, interventions targeting on these factors were recommended.
\end{abstract}

Keywords: Risky Sexual Behaviour; Construction Workers; Migration; Bahir Dar City; Ethiopia

\section{Background}

Risky sexual behavior is the major factor in rising rate of sexually transmitted infections (STIs) including HIV among adolescents and young adults. Adolescents typically have higher STI rates than other age groups and young person's susceptibility to HIV infection has been consistently linked to intractable higher risk sexual behaviors [1,2]. Adolescents and young adults have increased interest in the opposite sex, highly concerned with physical and sexual attractiveness, and are fre-

${ }^{*}$ Computing interests: authors declared that they have no computing interests. quently changing relationships. Besides, are risk takers more likely to make decisions about the future without adequately considering the consequences [3].

Young people were engaged in risky sexual activities, which could result sexually transmitted diseases including HIV infection. And it was suggested that many young people have got information from different sources with regard to HIV/AIDS; however, the problem is to bring about behavioral change [4].

Young people were at the heart of HIV/AIDS pandemic; globally in 2010, out of estimated 2.7 million people newly infected with the virus $41 \%$ were young people [5]. In Ethiopia according to Antenatal Care Sen- 
tinel surveillance (ANC), the prevalence of HIV/AIDS among young people of age 15 - 24 years was 2.6\% [6].

In Sub-Saharan Africa adult HIV/AIDS prevalence was 5\% in 2009 and the main risk factor for HIV transmission were population movement, poverty, unequal distribution of wealth, lack of education, inequalities and various cultural influences $[7,8]$.

Different studies declared that epidemiology of HIV/ AIDS are highly related to migration. In most sub Saharan African countries population movement and HIV/ AIDS are linked to heterosexual transition fueled by rampant sexual transmitted infections (STI), multiple and commercial sexual relation, low condom use, poor access to health service and other social-cultural and economic factors related to population movement $[9,10]$.

Besides evidences indicated that social-cultural and economic factors which placed construction a worker in high risk situation were the movement of people from their rural area with unstable sexual partner, fragmented social network, reduced availability and accessibility of health service and economic transition which exposed construction worker to practice sexual risk taking behavior [11]. In Ethiopia particularly in the study area construction industry is on rising and deriving young people from rural area to cities to be the construction worker, and this could open a door for having risky sexual practices among construction workers. However there is no information on risky sexual practices among construction workers in northwest of Ethiopia. Therefore, the objective of the study was to assess the prevalence of risky sexual practices and associated factors among construction workers in big construction enterprises in Bahir Dar city.

\section{Methods and Materials}

Cross sectional quantitative study design was conducted among workers in big construction enterprises in Bahir Dar city in March 2012. This study was conducted in northwest part of Ethiopia at a distance of 565 kilometers from capital city (Addis Ababa) among workers at big construction enterprises in Bahir Dar city.

Bahir Dar city is the capital city of Amhara regional state and is one of the cities in Ethiopia in which investment is rapidly growing and construction investment is one of which involving many young people. The expansion of construction enterprises called many people living in rural areas to migrate and being labor workers in these companies. Adolescent and young adult construction workers at big construction enterprises in Bahir Dar city were eligible for this study.

The sample size was calculated using EPI INFO version 3.5.1 for cross-sectional studies from previous study of frequency of disease in un exposed group 15\%, OR
2.2 were taken, and assumptions of 95\% confidence level, $80 \%$ power were considered and additional non response rate of $10 \%$ was taken [12]. Samples of 376 big construction works were addressed in the study.

The respondents were selected from the target population using simple random sampling method among big construction enterprise workers. First big construction enterprise sites were selected from the whole construction enterprises in Bahir Dar city based on the criteria that a certain construction enterprise leveled as big. Then list of construction workers were collected from all big construction enterprises. Then the sample size 376 individuals were selected from list of workers these big construction enterprises using computer generated identification numbers.

Data were collected using face to face interview by using structured questionnaires. The questionnaire was adopted from reviewed literatures and the items in the tool addresses issues like socio demographic variables, sexual behaviors, family and peer factors, institutional factors, substance and alcohol use and multiple sexual partners.

Our outcome measure was risky sexual behavior. The first question asked to measure the dependent variable was: "Have you ever had sexual intercourse?"; The responses were "Yes" or "No". Individuals answered "Yes" were asked further questions "at what age did you had your first sex?" and "what is your marital status?" individuals who responded married, asked "have ever had sex out of your spouse in the last 12 months?" and individuals answered "single", "divorced" or "windowed" asked a question "have you had sex in the last twelve months?" responses were "Yes" or "No" respondents answered "Yes" asked a next question did you used condom in each of your sexual intercourse? Responses were "Yes" and "No" and "with how many sexual partners did you had sex in the last twelve months?" responses were "one" and more than "one". Unmarried female respondents who started sex were asked another question have you ever had unwanted pregnancy? Responses were "Yes" and "No", individuals who responded yes asked further question have you ever induced abortion? Responses were "Yes" and "No", respondents answered "Yes" asked where did you have abortion?

Finally, individuals responded: age of first sex less than 18 years, or married individuals reported sex out of marital partner, or (single, divorced or windowed) individuals answered had more one sexual partner in the last 12 months, or inconsistent condom use with non marital partner, or unmarried female respondents reported unwanted pregnancy or abortion were regarded as have risky sexual behavior. 
The questionnaire was initially prepared in English and translated in to local language Amharic in order to obtain the required information from the respondents and was translated back to English to check for any inconsistencies or distortions. Pre-test was done among 20 construction workers in big construction enterprises not involved in the main study. Eight post graduate students as data collectors, four supervisors and the principal investigators were recruited during the field work.

Data collectors and supervisors were trained for two days to make them familiar with the questionnaires; the way how to ask questions and guide the over all process of data collection. The data collection was conducted under close supervision of principal investigators and supervisors. Each day the whole questionnaires filled on the same day were checked for completeness and consistency, in addition meetings were held to discuss the problems might encounter. Data were double-entered onto the EPI-data Version 3.1 software by defining legal values for each variable and setting skip patterns. The doubleentered data were validated and exported to SPSS version 16 software package.

Univarate and Bivarate analysis were computed to see the frequency distribution and to test whether there is association/difference/between risky sexual behaviour and selected independent variables. Factors associated with risky sexual practices at bivariate were identified and the variables with $p$-value of 0.20 and less were taken to multivariable analysis and the model was built with backward elimination. Finally, the $p$-values less than 0.05 were considered statistically significant.

Ethical clearance was obtained from ethical review committee of Gondar University and Addis continental institute of public health and communicated with regional health bureau before the time of data collection. Letter of permission was obtained from the health bureau and from each construction enterprises. The confidentiality of information was maintained by excluding personal identifiers; data were collected after securing informed consent from every respondent.

\section{Result}

\subsection{Social-Demographic Characteristics}

A total of 376 big enterprise construction workers with a response rate of $100 \%$ completed the questionnaire and included in the analysis. Out of the total respondent, 215 (57.2\%) were males and 161 (42.8\%) were females. Majority of the study participants 307 (81.6\%) were in the age group of $20-24$ with the mean age of $20.35 \pm 1.5$ SD. Two hundred seventy four (72.9\%), 64 (17\%), 38 $(10.1 \%)$ of the respondents of the study were never married, married, and divorced respectively. The majority of the respondents 139 (37\%) were from grade $5-8,60$ (16\%) were from grade 9 - 10, 59 (15.7\%) were from grade 1 - 4, 57 (15.2\%) were unable to read and write, 32 (8.5\%) were read and write, 29 (7.7\%) were above grade 10 . The average monthly income of the study participant was 905 birr, and $52.7 \%$. They were earning less than 500 birr per month. The majority of 226 (60.1\%) study subjects were migrant from the nearby rural community and economic problem106 (47.1\%) was the main reason to do so (Table 1).

Table 1. Socio demographic variables of big construction enterprise workers in Bahir Dar city, March 2012.

\begin{tabular}{|c|c|c|}
\hline Variables & Number (376) & Percent \\
\hline \multicolumn{3}{|l|}{ Sex } \\
\hline Male & 215 & 57.2 \\
\hline Female & 161 & 42.8 \\
\hline \multicolumn{3}{|l|}{ Age } \\
\hline $15-19$ & 69 & 18.4 \\
\hline $20-24$ & 307 & 81.6 \\
\hline \multicolumn{3}{|c|}{ Age of the first marriage $(n=95)$} \\
\hline $15-19$ & 50 & 52.6 \\
\hline $20-24$ & 45 & 47.4 \\
\hline \multicolumn{3}{|l|}{ Religion } \\
\hline Orthodox & 361 & 96.0 \\
\hline Islam & 15 & 4.0 \\
\hline \multicolumn{3}{|l|}{ Marital status } \\
\hline Single & 274 & 72.9 \\
\hline Married & 64 & 17 \\
\hline Divorced & 38 & 10.1 \\
\hline \multicolumn{3}{|l|}{ Ethnicity } \\
\hline Amhara & 362 & 96.3 \\
\hline Tigre & 14 & 3.7 \\
\hline \multicolumn{3}{|l|}{ Educational status } \\
\hline Able to read and write & 32 & 8.5 \\
\hline Un able to read and write & 57 & 15.2 \\
\hline Grade 1 - 4 & 59 & 15.7 \\
\hline Grade 5 - 8 & 139 & 37.0 \\
\hline Grade 9 - 10 & 60 & 16.0 \\
\hline Above grade 10 & 29 & 7.7 \\
\hline \multicolumn{3}{|l|}{ Monthly income } \\
\hline$<500$ & 198 & 52.7 \\
\hline $500-1500$ & 172 & 45.7 \\
\hline$>1500$ & 6 & 1.6 \\
\hline \multicolumn{3}{|l|}{ Causes of migration $(n=218)$} \\
\hline Absence of work & 34 & 9.0 \\
\hline Absence of farming area & 106 & 28.2 \\
\hline Decrement of income & 39 & 10.4 \\
\hline Conflict & 39 & 10.4 \\
\hline
\end{tabular}




\subsection{Sexual Behavior}

Out of the 376 respondents 259 (68.88\%) reported to have ever had sexual intercourse (unmarried) which include 155 (59.8\%) were males, 104 (40.2\%) were females. Among 155 (59.8\%) male respondents who ever had sexual intercourse, 30 (8\%) of them had sex with commercial sex worker of these 20 (66.7\%) of the study participants had sex with commercial sex workers without condom used. One hundred sixty five (44.2\%) study participant ever get voluntary counseling test, 82 (49.7\%), 40 (24.2\%), 7 (4.2\%), 34 (20.6\%), 2 (12\%) in government hospital, the government clinic, private health center voluntary counseling test center and family planning respectively. Of 46 study subjects who ever faced unwanted pregnancy 39 (84.8\%) were faced abortion of these 15 (34.1\%), 18 (40.9\%), 11 (25\%) abort in health center, self drug administration and traditional birth attendants' respectively. The mean age at the first sexual intercourse was $18.4( \pm 1.99 \mathrm{SD})$ years. The minimum age for the first sexual intercourse for male and female were 16 and 15 respectively. The maximum age of the first sexual intercourse for both male and females were 24 . Of the total 276 age of the first sexual intercourse, 82 (29.7\%) males and 100 (36.3\%) female were found in the age group of 15 - 19 and 79 (28.6\%) male and 15 (5.4\%) female were found in the age group of $20-24$. Of the total of 376 study subjects, 169 (44.9\%) had risky sexual behavior of theses 77 (35.8\%) were males and 92 (57.1\%) were females (Table 2).

\subsection{Logistic Regression Analysis between Risky Sexual Behaviours and Predictor Variables among Big Construction Workers in Bahir Dar City, March 2012}

This study declared that female construction workers were about four times more likely to have had risky sexual practices than males $(\mathrm{AOR}=3.86,95 \% \mathrm{CI}$ : 2.34 6.37). This study indicated that educational status was a significant predictors of risky sexual behaviour among construction workers, specially individuals whose educational status was from grade 1 to 4 were about 12 times more likely to engaged in risky sexual practices than those individuals whose educational level was tenth grade or more (AOR = 12.13, 95\% CI: 1.84 - 79.78).

Marital status was one of independent predictors of risky sexual behaviour among the target population; divorced individuals were about five times more likely to have had risky sexual activities than married individuals $(\mathrm{AOR}=4.63,95 \% \mathrm{CI}: 1.32$ - 16.12). Construction workers whose first sexual intercourse in the age ranges of 15 - 19 years were about three times more likely to have had risky sexual behavior than whose first sexual com-
Table 2. Percentage distribution of sexual characteristics by se among big construction enterprise workers in Bahir Dar city, March 2012.

\begin{tabular}{cccc}
\hline Variable & Male $\boldsymbol{n}(\%)$ & Female $\boldsymbol{n ( \% )}$ & Total $\boldsymbol{n ( \% )}$ \\
\hline \multicolumn{4}{c}{ Ever had sexual practices } \\
\hline Yes & $155(72.1)$ & $104(64.6)$ & $259(68.9)$ \\
No & $60(27.9)$ & $57(35.4)$ & $117(31.1)$ \\
\hline \multicolumn{5}{c}{ Age at the first sexual intercourse $(n=276)$} \\
\hline $15-19$ & $82(50.9)$ & $100(87)$ & $182(65.9)$ \\
$20-24$ & $79(49.1)$ & $15(13)$ & $94(34.1)$ \\
\hline \multicolumn{5}{c}{ Risky sexual behavior $(n=376)$} \\
\hline Yes & $77(45.6)$ & $92(54.4)$ & $169(44.9)$ \\
No & $138(66.7)$ & $69(33.3)$ & $207(55.1)$ \\
\hline
\end{tabular}

mencement was in the age of $20-24$ years $(\mathrm{AOR}=2.89$, 95\% CI: 1.70 - 4.91).

The odds of having risky sexual behaviour among construction workers who had sexual partner currently on the time of the study were about 0.6 times less likely to have had risky sexual behaviours than works who did not have sexual partner (AOR = 0.6, 95\% CI: 0.38, 0.96).

Besides, female construction workers who had abortion in their life and construction workers who had sex with causal partner in the last twelve months were more than 40 and 7 times likely to have had risky sexual behavior than those who never had abortion and sex with causal partner in the last twelve months (AOR $=40.70$, 95\% CI: 3.56 - 465.40 and AOR = 6.99 (4.03 - 12.16) respectively (see Table 3 ).

\section{Discussion}

In Ethiopia limited information is available about the sexual behavior of construction workers and their contribution to the spread of HIV/AIDS. The prevalence of risky sexual behavior in this study is $44.9 \%$. This prevalence is associated with, sex, educational status, marital status, age at the first sexual intercourse, age at first marriage, presence of current sexual partner, ever had abortion and casual sex in the last 12 months. The prevalence of risky sexual behaviour in this study is higher than in Kombelcha which is $35.5 \%$ among daily laborers and lowers than study done in Asosa (47\%) behavioral Survey for HIV/AIDS infection among the general population and commercial sex workers. Thus the reason for the lesser in this study with that of Asosa could be due to the involvement of commercial sex workers while the greater the prevalence could be due to: in this study both males and females construction worker were involved, isolated work site for short period i.e. Short term work on sites often located around isolated communities, may lead to members of the local community, especially poor women, 
Table 3. Predictors of risky sexual behaviours among construction workers in Bahir Dar city, March 2012.

\begin{tabular}{|c|c|c|c|c|}
\hline \multirow{2}{*}{ Variables } & \multicolumn{2}{|c|}{ Risky sexual behaviour } & \multicolumn{2}{|c|}{ OR (95\% CI for OR) } \\
\hline & Yes & No & Crude & Adjusted \\
\hline \multicolumn{5}{|l|}{ Sex } \\
\hline Male & 77 & 138 & 1.00 & 1.00 \\
\hline Female & 92 & 69 & $2.39(1.57-3.63)$ & $3.86(2.34-6.37)$ \\
\hline \multicolumn{5}{|l|}{ Age } \\
\hline $15-19$ & 30 & 39 & 1.00 & 1.00 \\
\hline $20-24$ & 139 & 168 & $1.08(0.64-1.82)$ & $0.29(0.03-2.89)$ \\
\hline \multicolumn{5}{|l|}{ Educ. status } \\
\hline Unable to read and write & 14 & 18 & $2.04(0.70-5.97)$ & $13.49(0.09-19.02)$ \\
\hline Able to read and write & 31 & 26 & $3.13(1.19-8.23)$ & $2.06(0.31-13.87)$ \\
\hline Grade 1 - 4 & 34 & 25 & $3.57(1.36-9.36)$ & $12.13(1.84-79.78)$ \\
\hline Grade 5 - 8 & 66 & 73 & $2.37(0.98-5.72)$ & $2.59(0.51-13.13)$ \\
\hline Grade 9 - 10 & 16 & 44 & $0.95(0.35-2.58)$ & $1.08(0.17-6.81)$ \\
\hline$>$ Grade 10 & 8 & 21 & 1.00 & 1.00 \\
\hline \multicolumn{5}{|l|}{ Marital status } \\
\hline Married & 112 & 162 & 1.00 & \\
\hline Single & 35 & 29 & $1.75(1.01-3.02)$ & $1.7(0.68-4.24)$ \\
\hline Divorced & 22 & 16 & $1.99(1.00-3.96)$ & $4.63(1.32-16.12)$ \\
\hline \multicolumn{5}{|l|}{ Age at first sex intercourse } \\
\hline $15-19$ & 123 & 59 & $3.07(1.83,5.15)$ & $2.89(1.70,4.91)$ \\
\hline $20-24$ & 38 & 56 & 1.00 & 1.00 \\
\hline \multicolumn{5}{|c|}{ Discussion with family on sexual issues } \\
\hline Yes & 19 & 39 & 1.00 & 1.00 \\
\hline No & 150 & 168 & $1.83(1.02-3.31)$ & $1.45(0.43-4.92)$ \\
\hline \multicolumn{5}{|c|}{ Discussion with peer on sexual issue } \\
\hline Yes & 111 & 58 & 1.00 & 1.00 \\
\hline No & 131 & 76 & $0.90(0.59,1.38)$ & $1.22(0.50-3.02)$ \\
\hline \multicolumn{5}{|c|}{ Friends who motivate for condom use } \\
\hline Yes & 54 & 87 & 1.00 & \multirow{2}{*}{$1.45(0.91-2.32)$} \\
\hline No & 115 & 120 & $1.54(1.01-2.36)$ & \\
\hline \multicolumn{5}{|c|}{ Peer pressure to go church or mosque } \\
\hline Yes & 133 & 169 & 1.00 & \\
\hline No & 36 & 38 & $1.21(0.72-2.00)$ & $1.32(0.69-2.48)$ \\
\hline \multicolumn{5}{|c|}{ Presence of current sexual partner } \\
\hline Yes & 62 & 49 & $1.87(1.20-2.92)$ & $0.6(0.38,0.96)$ \\
\hline No & 107 & 158 & 1.00 & 1.00 \\
\hline \multicolumn{5}{|l|}{ Ever used stimulant } \\
\hline Yes & 38 & 26 & $2.02(1.17-3.49)$ & $1.26(0.67-2.35)$ \\
\hline No & 131 & 181 & 1.00 & 1.00 \\
\hline \multicolumn{5}{|c|}{ Ever faced unwanted pregnancy } \\
\hline Yes & 43 & 4 & $13.7(4.58-40.72)$ & \\
\hline No & 48 & 61 & 1.00 & $1.67(0.34-8.27)$ \\
\hline \multicolumn{5}{|l|}{ Ever faced abortion } \\
\hline Yes & 43 & 1 & $58.6(7.78-440.54)$ & $40.70(3.56-465.40)$ \\
\hline No & 47 & 64 & 1.00 & 1.00 \\
\hline \multicolumn{5}{|c|}{ Casual sex in the last 12 months } \\
\hline Yes & 147 & 109 & $6(3.56-10.15)$ & $6.99(4.03-12.16)$ \\
\hline No & 22 & 98 & 1.00 & 1.00 \\
\hline
\end{tabular}


to engage in transactional and commercial sex with construction workers who have disposable income. Besides, the isolated work sites lead to a lack of social cohesion and social norms governing behavior of workers, which may lead to engagement in risky sexual behavior, singlesex hostels and limited home-leave i.e. construction workers often have no choice but to live in single-sex hostels without the option of being accompanied by their partners and families. In addition, they may have limited home-leave which further isolates them from their partners. These circumstances may lead some workers to seek other relationships. There is limited availability of entertainment at or around construction sites. Workers are often isolated from traditional norms and support systems that regulate behavior in stable communities, coupled with feelings of activities, and isolation, which can result in a disregard for health [12,13].

In this study, 211 (56.1\%) study subjects were motivated by peer to practice risky sexual behavior. This is greater than the study conducted in Addis Ababa among the youth (41\%). This difference could be due to civilizations of parents and other socio economic factors [14]. While a majority of adolescents and young adults report having discussions with their partners about contraception and their comfort level with specific types of sexual activity, fewer have engaged in dialogue about STDs and HIV/AIDS one can supper impose with the other [15].

Age at the first sexual intercourse is frequently used as a proxy for first exposure of sexual intercourse and the risk of acquiring sexually transmitted infection including HIV/AIDS, unwanted pregnancy and abortion. Behavioral science researchers agree that abstinence from sex before marriage and delay of sexual debut are among the important strategies that help to reduce the spread of HIV/AIDS, especially among youths [16]. In this study the mean age at the first sexual intercourse is $18.4( \pm 1.99$ $\mathrm{SD})$ years. The majority of sexually active respondents 169 (61.6\%) were never married and 44 (28.4\%) female construction workers had abortion. This finding (mean age) is in agreement with studies done in Asosa, the mean age is 18 years, Kmbelcha 16.8 - 21.7 years, in Addis Ababa 19 years, among road construction workers (from Tatek in Oromia Natiotional Regional State, Shew-Robit and Woreta, Maichew in Tigray, Jijiga in Somali, Wolkite, Butajira, and Hossana) which was 19.6 and the mean age of the first sexual intercourse this study is disagree with that of the mean age at the first sex among factory workers in Bahir Dar Textile which was 31.1 years the difference is due to the study subject's age ranges from 15 - 59 [17].

From the above findings we can understand that more than half $(73.4 \%)$ of the study subjects have already started sexual intercourse of which $65.9 \%$ were found in age ranges of 15 - 19 and 34.1\% were found in the age groups of $20-24$ which is against the rule of abstaining from sex before marriage and delaying sexual debut.

The majority of 226 (60.1\%) study subject were migrant from the nearby rural community and economic problem 106 (47.1\%) was the main reason to do so. This finding is in agreement with studies done where emigrants are at risk of HIV/AIDS because of their risky sexual behaviour $[18,19]$. This might indicate that young rural adults often migrates to the town searching for work opportunity so as to make money and cope up with the economic problems encountered in the rural community [20]. Evidence showed that the among socio-cultural and economic factors which place construction worker at high risk situation is movement of people from their rural area with unstable sexual partner, fragmented social net work, reduced availability and accessibility of health services and economic transition which could exposed construction workers to practice sexual risk taking behavior [21]. This study declared that age first sexual intercourse is a significant predictors of risky sexual behaviour, respondents whose first sex in the age range 15 - 19 were about 3 times more likely have had sexual risk behaviour than individuals who had their first sex was from 20 - 24 years $(\mathrm{AOR}=2.89,95 \% \mathrm{CI}: 1.70,4.91)$. This is in line with other study where individuals who had earlier age were more likely to be engaged in risky sexual behaviour [22]. Besides, this study indicated that individuals who had casual sex in the last twelve months were about seven times more likely to be engaged in sexual risk behaviour than respondents who didn't had casual sex in the past twelve months $(\mathrm{AOR}=6.99,95 \% \mathrm{CI}: 4.03$ 12.16), this is in accordance with other study where having casual sex is associated risky sexual behaviour and which is usually regarded as risky for HIV transmission $[23,24]$. Moreover, only $165(44.2 \%)$ of respondents were voluntary to have VCT and a high proportion of youth continue to experiment with high-risk behavior. This might be due to low risk insight of the youth that predisposes to high-risk sexual activities. This finding strengthens the need to pay attention to the youth.

\section{Conclusions}

The findings of this study declared that the prevalence of risky sexual behavior among big construction enterprise workers is $44.9 \%$; showing that nearly half of respondents were engaged in sexual risk behaviour which demands the attention of all concerned bodies. Besides, several variables including sex, educational level, marital status, age at first sexual intercourse, presence of current sexual partner and casual sex in the last twelve months were found to be independent predictors of risky sexual behaviour among construction enterprise workers. There- 
fore, based on the main findings of the study urgent in Behavioral change communication (BCC)/Information Education Communication (IEC) activities should be done by the Woreda Health Offices, Woreda HAPCO and other organizations working on adolescents and young adults in a sustainable and organized manner to educate construction workers on the identified high risk sexual behaviors. Besides, enhance condom promotion activities which have indispensable use in prevention of both sexually transmitted diseases including HIV and unwanted pregnancies and their outcomes of unsafe abortion using different approaches like youth club, community volunteers, peer group and work place education.

Finally, the source population at large needs education on sexual risk behaviours and its consequences as a long term intervention which may likely to result HIV infection, illegal abortion and different socio economic crises among adolescent and young adults if left not intervened.

\section{Author's Contribution}

MK conceptualized the research problem, designed the study, conducted field work, analyzed the data and revised the manuscript.

ET was involved in supervision of the field work, revision of the research design, data analysis and revision of the manuscript for publication.

ZA was contributed in the revision of the research design, statistical analysis and prepared the manuscript.

All authors of the manuscript have read and agreed to its content.

\section{Acknowledgements}

The authors are grateful to all big enterprises in Bahir Dar city involved, data collectors and supervisors of the study. Finally our special gratitude goes to the participants of the study who shared their time to give their genuine responses.

\section{REFERENCES}

[1] M. T. Schechter, et al., "Effect Exposure Factors, Cofactors and HTLV-III Seropositivity on Number of Helper T Cells,” American Journal of Public Health, Vol. 78, No. 12, 1988, pp. 1534-1535.

[2] G. G. Pison, et al., "Risk Factor for HIV Infection in Rural Senegal," Journal of Acquired Immune Deficiency Syndromes, Vol. 6, No. 2, 1993, pp. 12-23.

[3] Jenny Nicholson MSW Student, "Risky Sexual Behaviour among Adolescents and Young Adults,” University of North Carolina Chapel Hill, 2012. http://www.docstoc.com/docs/38043379/

[4] M. Rweng, "Sexual Risk Behavior among Young People in Bamenda Cameroon,” International Family Planning
Perspectives, Vol. 26, No. 3, 2000, pp. 118-130.

doi: $10.2307 / 2648300$

[5] “Joint United Nations Programme on HIV AIDS,” Global HIV/AIDS Response, Epidemic Update and Health Sector Progress towards Universal Access, Progress Report, 2011.

[6] Ethiopian Health and Nutrition Research Institute (EHNRI), "Report on the 2009 Round Antenatal Care Sentinel HIV Surveillance in Ethiopia,” Addis Ababa, 2011.

[7] G. M. Stephenson and J. H. Davis, "Attitudes and Voting Behavior. An Application of the Theory of Reasoned Action,” Journal of Progress in Applied Social Psychology, Vol. 1, 1981, pp. 253-313.

[8] G. K. Ateka, "Factors in HIV/AIDS Transmission in SubSaharan Africa,” Journal of the World Health Organization, Vol. 79, No. 12, 2001, p. 168.

[9] A. Neal, M. D. Halsey, et al., "Sexual Behavior, Smoking and HIV-1 Infection in Haitian Women," Journal of the American Medical Association, Vol. 267, No. 15, 1992, pp. 2062-2066. doi:10.1001/jama.1992.03480150068039

[10] C. Jonathan, L. Mark, W. Brian, et al., "HIV/AIDS, Population Mobility and Migration in Southern Africa," Defining a Research and Policy Agenda, June 2005, pp. 166.

[11] G. S. Becker, "A Theory of the Allocation of Time,” The Economic Journal, Vol. 75, No. 4. 1965, p. 493. doi:10.2307/2228949

[12] K. Kanda, Y. Obayashi and R. A. Knowledge, “Attitude and Practice Assessment of Construction Workers for HIV/AIDS in Sri Lanka,” Journal of Infection in Developing Countries, Vol. 3, No. 8, 2009, p. 612.

[13] F. R. Booysen and J. Summerton, "Assessment of Poverty Risky Sexual Behavior, and Vulnerability to HIV Infection in South Africa," Journal of Health, Population and Nutrition, Vol. 20, No. 4, 2002, p. 287.

[14] P. A. Akwara, N. J. Madise and A. Hinde, "Perception of Risk of HIV/AIDS and sexual behavior in Kenya," Journal of Communicable Disease, Vol. 35, No. 3, 2003, pp. 385-389.

[15] A. Schwarzenegger, "HIV Risk Assessment of Migrant Latino Day Laborers. Predictors of Condom Use in Latino Migrant Day Laborers,” Journal of Behavioral Science, Vol. 33, No. 1, 2009, p. 91.

[16] N. S. N. Htun and W. Phoolcharoen, "HIV/AIDS Risk Behaviors among Myanmar Migrants in Bangkok, Thailand,” Journal of Health Research, Vol. 23, No. 6, 2009, pp. 87-88.

[17] G. Mitike, et al., "HIV/AIDS Behavioral Survilance Survey (BSS),” Ethiopia, 2005. http://www.etharc.org/resources/download/finish/33/50

[18] A. E. Biddlecom, "Migration Sexual Behaviour and the Risk of HIV in Keniya," International Migration Review, Vol. 33, No. 4, 1999, pp. 833-856. doi:10.2307/2547354

[19] K. C. Poudel, M. Jimba, J. Okumura, A. B. Joshi and S. Wakai, "Migrants' Risky Sexual Behaviours in India and at Home in Far Western Nepal," Tropical Medicine \& International Health, Vol. 9, No. 8, 2004, pp. 897-903. 


\section{doi:10.1111/j.1365-3156.2004.01276.x}

[20] O. L. Olusheyi and R. M. Kanthula, "Factors that influence Attitudes and Sexual Behavior among Constituency Youth Workers in Oshana Region, Namibia African,” Journal of Reproductive Health, Vol. 14, No. 1, 2010, p. 55.

[21] G. S. Becker, “A Theory of the Allocation of Time,” The Economic Journal, Vol. 75, No. 4, 1965, p. 493. doi:10.2307/2228949

[22] J. Greenberg, L. Magder and S. Aral, "Age at First Coitus. A Marker for Risky Sexual Behavior in Women,” Sexually Transmitted Diseases, Vol. 19, No. 6, 1992, pp. 331-
334. doi:10.1097/00007435-199211000-00006

[23] W. Van den Boom, I. Stolte, T. Sandfort and U. Davidovich, "Serosorting and Sexual Risk Behaviour According to Different Casual Partnership Types among MSM: The Study of One-Night Stands and Sex Buddies," AIDS Care, Vol. 24, No. 2, 2012, pp. 167-173.

[24] Z. Mor, U. Davidovich, N. Bessudu-Manor, M. McFarlane, G. Feldshtein and D. Chemtob, "High-Risk Behaviour in Steady and in Casual Relationships among Men Who Have Sex with Men in Israel,” Sexually Transmitted Infections, Vol. 87, No. 6, 2011, pp. 532-537. doi:10.1136/sextrans-2011-050048 